\title{
Role of Entrepreneurial Cultural Support and Locus of Control as Predictors of Entereprenurial Intuition among Private University Students
}

\author{
Ojewumi Aderemi Kehinde \\ Department of Psychology, \\ Obafemi Awolowo University, \\ Nigeria
}

DOI: https://doi.org/10.36941/jicd-2021-0012

\section{Abstract}

The study examined the predictive role of entrepreneurial cultural support (ECS) and locus of control (LOC) on entrepreneurial intuition (EI). This was to identify factors that predict EI among undergraduates' of a private university, in Osun state, Nigeria. The study adopted a descriptive research design. For the study, primary data was used while the population of the study consisted of final year undergraduate students'. A purposive sampling technique was used to select 362 students. Their age ranged from 16 to 30 years with a mean age of 21.43 years, SD (2.65). Four standardized psychological scales were used in the study. These were entrepreneurial intuition, ECS and LOC scale. Data collected were analysed using zero order correlation and multiple regression. The result shows a significant positive relationship between ECS and entrepreneurial intuition $[r(360)=0.76, p<.01]$. There was also significant positive relationship between LOC and entrepreneurial intuition $[r(360)=$ $0.58, p<.01$. The study concluded that there was predictive role ECS and LOC on entrepreneurial intuition among undergraduates. It is therefore recommended that trained psychologists should develop psychological intervention programmes which should be tailored toward improving ECS and LOC which invariably can help improve and enhance EI among undergraduates.

Keywords: Entrepreneurial intuition, Entrepreneurial cultural support, Locus of control, Undergraduates 


\section{Introduction}

In this age of accelerated technological development, the world has become a global village which end result is the stimulation of rapid growth in business endeavour except that it has, at the same time created a worldwide competition within and between nations. This harmonization in the world economy may have been made possible through the process of entrepreneurial activity of individuals and organizations from all over the world (Acs \& Varga, 2005; Kritikos, 2014). Entrepreneurship alludes to the concept of developing and running an enterprise with the ultimate aim of turning in profit from the initial risk taken. Entrepreneurship being the backbone of any economy requires the budding entrepreneur to identify and judge business opportunities as fast as possible. Intuition has been identified as a variable that can be used to arrive at the right decision even when all other parameters are pointing negative or positive. This then makes the entrepreneur to record higher success rate. Entrepreneurship is therefore the readiness to engage in a new business or enlarge the already establishes one. Numerous researchers have established that entrepreneurship has been playing crucial roles in the economic noticeable development of the expanding global marketplace (Kritikos, 2014; Imafidon, 2014). Haven thus realised the importance of entrepreneurship, serious commitment has been given towards its concepts and activity taking into consideration its vital roles on economic development, creation of job opportunities, sources of innovation as well as increase of country's yield or production (Almahry, Sarea \& Hamdan, 2018).

Nonetheless, Umukoro and Okurame (2017) were both of the opinion that though entrepreneurism may be useful in generating employment and technological development, this perceived success may sometimes rely upon intuitive ability of entrepreneurs to make business decisions under accelerating and overwhelmed business situations. As it were, numerous authors have implicated various variables in entrepreneurial behavior. Been that as it may, the present study is interested in establishing an empirical foundation for the influence of ECS and LOC on El among university students. The present article submits detail of the background to the study, problem statement, methods, findings and closing observations.

There has not been a commonly accepted definition of intuition as can be confirmed in literature. The area of contention has to do with where intuition actually occurs. For some researchers, intuition occurs in consciousness (Simon 1987; Agor 1998); others rigidly maintain that logical thinking does not have a role to play in intuition. Another school of thought believe that intuition appears where consciousness meets subconscious, and ready-made answers begin to emerge only when the mind of a decision-maker has to solve a real problem (Goldberg 1983; Rowan 1986). Another area of contention has to do with what represent the constituents of intuition and the degree to which intuition is used, which has been known to be influenced by many factors, such as knowledge, skills, experience and the business environment (Malewska, 2018). A host 
of authors are however in agreement with the fact that intuition go along with and reduces every decision-making process in varying degrees. Intuition facilitates decisionmaking process in a situation where there is deficiency of adequate information or when one is under pressure for time. In the opinion of Laszczak (2010), intuition is less often refers to as asudden 'revelation', difficult to define knowledge or a kind of instinct.

Researchers have insinuated that entrepreneurs who possess intuitive ability are helped to make priceless decisions even when the market is overwhelmed or the entrepreneur is facing a crisis (Mitchell, Friga, \& Mitchell, 2005). This may then be a reason why a lot of accomplished entrepreneurs that abounds today credit their success stories to El. In this regard, successful entrepreneurs like Donald Trump, Bill Gates, OprahWinfrey and Steve Jobs, that have been accorded to be successful in their chosen fields, attributed their achievement to their personal intuition notwithstanding other elements (Mills, 2012). Furthermore, McMullen and Shepherd (2006) established that managers that are more intuitive in the way they make decision making were more efficient when compared to their others who implemented analytical or logical decisions. Hence, the concept of intuition has eventually turned into a pertinent field that is currently being giving attention in psychology and entrepreneurism. This goes to show that the achievement of a budding entrepreneur is to a large extent contingent on their El that operates as an underlying channel that could possibly evoke not only personal initiatives towards entrepreneurship but at the same time makes a success of the business when it eventually gets running. For this reason, the need to develop the capability of exercising intuition effectively cannot be overemphasized. It is then critical that researchers know about the role intuition plays in the identification, evaluation as well as exploitation of business opportunities as researchers advocate that it could be extremely beneficial if entrepreneurs integrate intuition into the entire process of entrepreneurship (Dutta \& Crossan, 2005; Baldacchino, Ucbasaran, Cabantous, \& Lockett, 2014). On the contrary, not many researchers in Nigeria have dared to empirically investigate intuition in enterprise development. This therefore implies that a great void exists in the academic literature with reference to the role of intuitive predispositions in entrepreneurism and this has provoked appeals for scholarly investigation.

As highlighted by Bird (1988), the way an individual think may significantly impact intention which is part of decision making process. In cognitive psychology, cognitive style that is also known as 'thinking style' is defined as the way individuals think, perceive and remember information (Bird, 1988). The concept of cognitive style is regarded as fundamental to entrepreneurship and management based on the fact that differences and commonalities in cognitive styles may to a great extent impact decision making process and involvement in entrepreneurial activity, and for that reason, the success of the business. This is why cognitive style was categorized into several distinct facets (Allinson \& Hayes, 1996). This complexity of cognitive styles clearly illustrates the various ways by which the duality of human consciousness is understood. While the left 
hemisphere of the brain is associated with a linear processing of information in sequence that is mainly accountable for rational or 'analytical' thinking, the right hemisphere of the brain on its own conforms to a unified, simultaneous treatment of numerous inputs, a way of thinking typically used for spatial orientation or understanding of visual images cognitive style that is indicated as 'intuition' (Castellano, Maalaoui, Safraou \& Reymond, 2014). Conversely, quite a lot of studies have underscore the necessity to conduct more in-depth analysis on the conceptualisation of intuition and how not only executives but also entrepreneurs can use it in an efficient and clever way during the course of decision making that they face regularly (Malewska, 2018; Umukoro \& Okurame 2017;Sadler-Smith \& Shefy, 2004; Hodgkinson et al., 2009).This assertion was also supported by Kickul, Gundry, Barbosa, and Whitcanack $(2009,2010)$ when they asserted that persons with intuitive cognitive approach are known to have a higher self-belief in their personal capacity to investigate and identify opportunities wherever they may be (searching phase),

In terms of theory that that gave rise to intuition, the cognitive-experiential selftheory (CEST) by Epstein is well known and recognised (Epstein, 1991, 2008, 2010). This theory proposed that people function by way of two cognitive systems. One system is referred to as the 'experiential system' which is noted to be automatic learning system in nature; while the second one is called the 'rational system'. This can be likened to a conscious reasoning system where rationality is employed. The systems function parallelly and are synergistic in nature therefore; all behaviours are an offshoot of a mixture of the above mentioned systems. When the rational system blends with the experiential system that is responsible for our daily intuition, then, exhibition of complex behaviours such as creativity and wisdom' cannot be ruled out (Epstein, 2008). Epstein (2010) in addition states that the more the experiential/intuitive system is fast, involuntary and empirical in nature, then, the less the demand that will be made on the cognitive resources since it can be perfectly tailored to day-to-day patterns behaviour. Harteis, Koch, and Morgenthaler, (2008) when writing on the situation of investigations on intuition, additionally revealed the sort of acts that intuition permits: rapid (in response to demanding circumstances as a case in point) and startling ('astonishing in performance level'). Accordingly, CEST proposed that insight may be amongst the cognitive process that accounted for why veteran entrepreneurs can leverage their immense understanding and elaborate mental frameworks to boost how they are able to identify opportunities (Umukoro \& Okurame, 2017).

Intuitive mechanism which entails the harmonising of environmentally related stimuli with some profound belief (subconscious) categories (Dane \& Pratt, 2007) is conceptualised in CEST as being experientially-derived and holistically-oriented (Epstein, 2003; Epstein 2010), that is understood to be decisive in identifying opportunities. Only of late has CEST has been applicable to the domain of entrepreneurship (Cerni, Curtis, \& Colmar, 2014). From the point of view of CEST, human in general, including entrepreneurs are presumed to process information bidirectionally which comprise of 
the logical (analytical) and experiential (intuitive) systems. The upshots of this processing result in how entrepreneurs feel, construe events, decide on issues, and eventually behave (Epstein, 2014). A host of empirical investigations have recognized roles played by an assortment of psychological constructs on different entrepreneurial action. In this study, the emphasis is to establish an empiricalbasis for the influence of entrepreneurial cultural support and locus of control on entrepreneurial intuition.

\section{Cultural Support and Entrepreneurial Intuition}

Entrepreneurial cultural support is defined as a condition where new thoughts and inventiveness are normal, facing challenges is supported, disappointment is endured, learning is energised, advancements about item, procedure and the board are shielded and a ceaseless change is acknowledged as the bearer of opportunities (Foss \& Lyngsie, 2011). Likewise, Nhuta and Kapofu (2015), see culture of entrepreneurism as that which makes the quest for adventure and openings penetrates all aspects of the organisation or society.

As different societies are gifted with peculiar physical environments that may not be accessible elsewhere, it presupposes that for success and development to be attained, each society must implement appropriate patterns of behavior suitable to their environment. The effect of this is the formation of diverse cultural values and norms by societies and these may impact decisions on how to initiate, manage, respond to opportunities, and attract investors and how potential partners are sourced. Accordingly, supportive culture, as different from political, social, technological or financial situations, has pertinence not only for entrepreneurial activity but also the entire economic behaviour in a particular society (Shane, 1993; Shapero \& Sokol, 1982). Coming up with an acceptable definition of culture has been a challenge to researchers as there is no specific definition that is commonly accepted (McGrath et al., 1992). However, Culture as a concept emanate from the Latin word "cultura", which implies a process of doing things- the belief of a people in a particular locality or region. Luthans (1989) clarified that culture makes a more significant contribution when considering factors that influence attitude and other human personalities.

According to Hofstede (1980a), culture is a set of shared values, beliefs, and anticipated conduct of a set of people (Hofstede, 1980a). These values entrenched in various cultures define the extent to which societies recognise enterprising behaviours as for example motivation, openness to experience, and independent thinking. Hofstede (1980) also define culture as "mental programming", which alludes to the fact that the things that belong to a culture have been ingrained right from infancy periods and were learned in the course of one's existence (Hofstede, 1980), therefore, culture and its characteristics may affect how decisions are made by entrepreneurs. Cultural models vary within countries and between regions and consequently their impact on entrepreneurship are expected to vary. In accordance with these interpretations, the 
phrase culture is recommended as the needed value and ways of thinking prevailing among a set of people in a region or country that may promote entrepreneurial activity. In an age where unemployment is high among youths in Nigeria (Plecher, 2020), and the available resources for startup business and the already established firms is scarce, the need to make quick decision among entrepreneurs cannot be overemphasised. Decisions that relates to venturing into entrepreneurship, deciding on one or two of the numerous opportunities available, the best possible action to be adopted that will bring in maximum profit and the most advantageous expenditure has to be taken. As an entrepreneur facing enormous competition, a host of these decisions has to be taken in a relatively short period of time considering their impact on the business venture.

Unlike in the past where information is not readily available, information overflow is now the common problem (Sadler-Smith \& Shefy, 2004; Lank \& Lank, 1995). Now, entrepreneurs who need to make quick decisions may face difficulties in sorting out relevant and needed information from countless sources. Even with the advent of diverse IT based communication platforms, decision support systems (DSS) or even assignment of "Gatekeepers" (Shoemaker \& Vos, 2009), individual entrepreneurs still need to make the final decision sooner or later. This is when the entrepreneurial culture that pays premium on intuitive behaviour play its role. Although intuition has somewhat turn out to be a standard in decision making and using it has also been unavoidable, preference over and against intuitive decision making process is chiefly impacted by culture and its elements (Heinze, 2011; Pheysey, 1993). As humans, we are products of our environment and physical culture in terms of our behavior.Consequently, our home and environment account for the overwhelming differences in personal behaviour and ways of thinking which we exhibit and perceived by others.

In as much as a group of people share these behaviours and ways of thinking, then, it is believe that such behavior are culturally supported (Pheysey, 1993).Therefore, the manifestation of culture influences how decisions are likely to be made by entrepreneurs and business owners (Heinze, 2011; Pheysey, 1993). To buttress the issue of culture and intuition, Pheysey (1993) claim that there are differences between the Western and Eastern societies on how matters are perceived. While Western societies are inclined to explain occurrences based on science and pragmatism, the Eastern societies are prone to connect themselves with nature and see occurrences as given. In the same vein, she opined that "much of what 'we' know is subconscious and only surfaces in consciousness when conditions are ripped. While the western scientists know this, however, people from the Eastern part of the world pay greater regard to intuition" (Pheysey, 1993). In other words, intuitive decision making are known to have a higher acceptance level in the Eastern society than in Western societies. To accomplish a deeper insight in relation to the nature and practice of intuitive decision making in Nigeria, this survey will look at how cultural support affects intuitive behaviour. 


\section{Locus of Control and Entrepreneurial Intuition}

Entrepreneurs have been noted to have higher predispositions to demonstrate certain personality characteristics connected to decision making process. One of such characteristic is locus of control (LOC) which are in two dimensions referred to as internal and external locus of control. People that are predisposed to external LOC tend to attribute control over events in their lives to externality. To such people, the ability to influence what happens to them on a daily basis does not rest with them (Rotter, 1966; Shook et al., 2003). In contrast, having a high internal LOC increases the individual's perception of mastery and responsibility (Aboal \& Veneri, 2016; Vodă \& Nelu, 2019; Steinbauer, Rhew, Kinnamon, \& Fabian, 2014). Research has shown internal LOC to play a crucial part in the resolution to embark on a new venture (Vodă, \& Nelu, 2019; Aboal, \&Veneri, 2016; Entrialgo, Fernández, Vázquez, 2000; Mazzarol et al., 1999). Rotter (1992) argues that LOC affect the important area of problem-solving skills to be employed, and hence; is connected to forward planning, coping, level of persistent, practice, analysing events in order to make decisions and finally, locating and making use of new found information and knowledge that can be used to attain goals.

Thus, the concept describe an essential component of human performance in everyday situations that maybe novel, ambiguous or changing; which is what entrepreneurs experience on a daily basis. And for the purpose of this paper, the experience of using intuition to make a decision in running and managing a small business where other rational methods might readily provide answers. With respect to intuition, it is reasonable to assume that such persons with internal LOC will attempt to acquire intuitive capability and control than persons with an external LOC, if they believe that such intuition and control will generate the intended results (Millet, 2005). If by chance efforts invested bring about financial and social benefits, entrepreneurs with an internal LOC would be expected to view intuition model more positively and value it more than non-entrepreneurs with an external LOC (Millet, 2005). Locus of control has therefore been established to directly predict decision making behaviour using intuition (Mehni \& Saeidipour; 2016; Hozoori et al., 2011). In contrast, individuals who are high on external LOC may on their part see and acknowledge intuitive behavior without using it. On the other hand, a host of entrepreneurs believes that they are able to use their skills, knowledge, and abilities to produce goods or provide services that are demanded by customers. This set of entrepreneurs therefore represents a more internal LOC (Mueller \& Thomas, 2001; Steinbauer, Rhew, Kinnamon, \& Fabian, 2014).Without a doubt, internal LOC has been well researched for development, and by and large understood as a phenomenon that distinguishes entrepreneurs from non-entrepreneurs and may therefore be a reason why such entrepreneurs accomplished so much in their chosen endeavour (Miller, 1983; Rotter, 1966; Rotter, 1992; Wiklund, Davidsson, \& Delmar, 2003). Therefore, it is envisaged that entrepreneurs' with robust locus of control will be prone to exhibit higher intuitive cognitive behavior in comparison to non- 
entrepreneurs.

In summing up, it is proposed that two aspects of the nature of the entrepreneurs which include ECS and LOC are influences that may drive propensity for intuitive behaviour among undergraduates interested in entrepreneurship. Entrepreneurs' likely tendency to make intuitive decisions if they have a robust cultural support system, internal LOC, high need for achievement give credence to the notion that such entrepreneurs may have a more sustainable business ventures compared to entrepreneurs who rarely make use of the traits. Such observations can help explain why entrepreneurs'individual differences in terms of intuitive decision making mechanism may be reason(s) why some entrepreneurs are more successful than others. Though many studies have investigated different antecedents of $\mathrm{El}$, yet variables such as ECS and LOC as forerunners of EI are to a greater extent non-existent. This survey accordingly endeavors to address these deficiencies by embracing a quantitative methodology in advancing knowledge into how these variables impact El among university students who may be future entrepreneurs.

For this study, the following hypotheses are therefore postulated

Hypothesis One: There will be significant positive relationship between entrepreneurial cultural support, locus of control and entrepreneurial intuition among university students.

Hypothesis Two: There will be joint and independent positive prediction of entrepreneurial cultural support and locus of control on entrepreneurial intuition among university students.

\section{Methods}

This quantitative investigation engaged a cross-sectional research approach. The research was executed among final year students at Oduduwa University- a private university in Osun State, South-Western, Nigeria. To test the stated hypotheses properly, a sample frame and a research design which authorised for the examination of El among students was developed. Undergraduate students were chosen for two basic reasons:1) they face an crucial career decisions and have to discover personal professional inclinations; 2 ) they embody a suitable population as regards the analysis of intuition, which then reduces the sample bias that may crop up while picking participants. An official letter was submitted to the Registrar's office of Oduduwa Universty, Ipetumodu, Osun State, Nigeria requesting approval for the conduct of the research among the students of the university. After securing authorization from the office of the Registrar's to carry out the study, the researcher visited the school to recruit two research assistants. The research assistants who were students of the school were informed about the study and entreated to enlist the collaboration of students in the various faculties that were selected.

The way and manner by which questionnaire were to be distributed and 
administered was diligently elucidated to the research assistants for proper understanding of what is expected from them. After this, the questionnaires and biodata information forms were handed over to the recruited personnel's. Completed questionnaires were taken back along with the finished biodata forms and arranged inside paper jackets supplied by the investigator. Out of the entire 420 questionnaires administered, only 398 questionnaires were effectively gotten back. From these, 36 questionnaires were repudiated due to deficient and/or improper responses. A total of 362 completed questionnaires were thus utilized for the final analysis. Completed questionnaires were coded into the SPSS software application. Zero-order correlation was used to test for the relationship between ECS, LOC and entrepreneurial intuition. On the other hand, Multiple regression was adopted to test for the joint and independent predictive role of entrepreneurial cultural support, locus of control, on entrepreneurial intuition

\subsection{Instrument}

A structured questionnaire was employed for data gathering during the course of this survey. The questionnaire consists of validated scales that measured constructs of entrepreneurial cultural support, locus of control, and entrepreneurial intuition. Properties of the instruments are described below.

\subsection{Entrepreneurial Cultural Support Scale}

Entrepreneurial cultural support was measured by adapting and modification of the 17 item local entrepreneurial culture developed by Breazeale, Fortunato, Allen IV, Hustedde, and Pushkarskaya (2015). The scale measures the local entrepreneurial culture of a place based on the perception of residents. The goal of the scale is to measure extensively the perception of both local and urban dwellers in respect of cultural support. The scale was scored on a five point likert scale of Strongly disagree, Disagree, Neutral, Agree, and Strongly agree. High scores represent higher levels of entrepreneurial cultural support while low scores portray lower levels of entrepreneurial cultural support. Cronbach's alpha internal reliability statistics between .70 and .88 were reported for each factor. In this study a Cronbach alpha of .83 was reported for this scale.

\subsection{Locus of Control}

Locus of control was measured using the 20 item LOC scale developed by Rotter (1966). The scale was scored with a Yes or No response. Some items on the scale reads " "If I do not succeed on a task I tend to give up" and "I usually convince others to do things my way". Results are interpreted along the following scores: 0 - 15 indicate Very strong 
external LOC, 20 - 35: External LOC, $40-60$ : Both external and internal locus of control, 65 - 80: Internal LOC, 85 - 100: Very strong internal LOC. In this study a Cronbach alpha of .48 was reported for this scale.

\subsection{Entrepreneurial Intuition Scale}

This section was measured using the 20 item Epstein, Pacini and Denes-Raj (1996) scale. The scale was scored on a likert format ranging from strongly agree to strongly disagree. Sample of the item on the scale reads "I double-check my information sources to be sure I have the right facts before making a decision" and "I generally make decisions that feel right to me". The author reports a reliability of 0.76 . In this study a Cronbach alpha of .88 was reported for this scale.

\subsection{Participants}

The sample for the study consists of three hundred and sixty two (362) undergraduate's students. The study used a purposive sampling technique for the survey and simple random sampling method to pick the actual participants. Therefore, the researcher only recruits' undergraduates' student who volunteer within the study area.The sample of the population of the study stood at 203 male students and 159 female students, which gave a total of 362 respondents. Their gender distribution shows, that 203 (56.1\%) were males, while $159(43.9 \%)$ were females. The ages of the participants ranges from 16-30 with a mean of 21.43 and SD of 2.65. In terms of religious affiliation, $275(76.0 \%)$ practice Christianity, $83(22.9 \%)$ practice Islamic religion while just 4 (1.1\%) practices other religion. In terms of respondent marital status 335(92.5\%) were single, 26(7.2\%) were married while $1(.3 \%)$ are separated.

\subsection{Hypothesis Testing}

Hypothesis One: The hypothesis which states that there will be significant relationships between entrepreneurial cultural support, locus of control and entrepreneurial intuition among undergraduate students of Oduduwa University was tested using zero order correlation and the result is presented in Table 4.1

Table 4.1: Zero-order correlation showing the relationship among entrepreneurial cultural support, locus of control and entrepreneurial intuition

\begin{tabular}{lcccccc}
\hline Variables & Mean & SD & $\mathrm{N}$ & 1 & 2 & 3 \\
\hline 1 Entrepreneurial cultural support & 36.85 & 8.49 & 362 & - & & \\
2 Locus of control & 26.83 & 2.81 & 362 & $.43^{* *}$ & - & \\
3 Entrepreneurial intuition & 67.08 & 13.16 & 362 & $.76^{* *}$ & $.58^{* *}$ \\
\hline
\end{tabular}

**. Correlation is significant at the 0.01 level (2-tailed). 
The result reveals that there was significant positive relationship between entrepreneurial cultural support and entrepreneurial intuition $[r(360)=0.76, p<.01]$. The result therefore supported the hypothesis. This finding implies that undergraduates who reported high level of ECS tend to also report high entrepreneurial intuition. There was also significant positive relationship between LOC and entrepreneurial intuition [ $r$ $(360)=0.58, p<.01]$. This finding also implies that undergraduates who reported high level of LOC orientation tend to have high entrepreneurial intuition.

Hypothesis Two: There will be joint and independent prediction of entrepreneurial cultural support, and locus of control on entrepreneurial intuition among undergraduate students of Oduduwa University. The hypothesis was tested using multiple regression analysis and the result is presented in Table 4.2

Table 4.2: Summary of Multiple Regression table showing joint and independent prediction of entrepreneurial cultural support and locus of control on entrepreneurial intuition

\begin{tabular}{lccccccc}
\hline Variables & $\beta$ & $\mathrm{t}$ & $\mathrm{P}$ & $\mathrm{R}$ & $\mathrm{R}^{2}$ & $\mathrm{~F}$ & $\mathrm{P}$ \\
\hline Entrepreneurial cultural support & 0.62 & 18.41 & $<.05$ & 0.81 & 0.66 & 354.86 & $<.05$ \\
Locus of control & 0.31 & 9.37 & $<05$ & & & & \\
\hline
\end{tabular}

From Table 4.2, result indicate that there was significant joint prediction of entrepreneurial cultural support and locus of control on entrepreneurial intuition among undergraduates of Oduduwa university $\left(R^{2}=.66, F(2,359)=354.86, p<.05\right.$. The $\left.R^{2}=.66\right)$ indicating that the independent variables (entrepreneurial cultural support and locus of control) explained $66 \%$ variation of the dependent variable (entrepreneurial intuition). Furthermore, ECS $(\beta=0.62, t=18.41, p<.05)$ and $\operatorname{LOC}(\beta=0.31, t=9.37, p<.05)$ independently predict entrepreneurial intuition among undergraduates. The stated hypothesis was also accepted.

\section{Results and Discussion}

The first hypothesis stated that there will be significant positive relationship between entrepreneurial cultural support, locus of control and entrepreneurial intuition among university students. For entrepreneurial cultural support and locus of control, the study finding was in line with the study hypothesis by identifying the significant influence of entrepreneurial cultural support and locus of control on entrepreneurial intuition. The reason why entrepreneurial cultural support and locus of control have a positive relationship with entrepreneurial intuition could be due to the fact that these variables are important resources that an individual need to acquire in order to have an instinctive capability to initiate, identify and act in response to business-related signals which can be beneficial to such person and the society. Entrepreneurial cultural support 
therefore may serve the role of allowing the entrepreneur the ability to access the answers and solution that resides within them by allowing them to draw from the adequate support provided by the relevant culture. The entrepreneur then leverage on the support system from the family, friends, government to dig deep into their subconscious mind for the answers needed to solve any particular problem being faced knowing the self assurance that he/she has the necessary backing for his decision. This may also translate into an improved self confidence that is an offshoot of LOC

The second hypothesis found that there was joint prediction of entrepreneurial cultural support, and locus of control on entrepreneurial intuition among university students. This shows that as the variables independently influence entrepreneurial intuition, they also work together to influence entrepreneurial intuition. The rationale for this finding maybe unconnected to the fact that once the context where the entrepreneur is operating appears to be conducive and supportive of entrepreneurship ideas, coupled with the fact that the individual also have the control over their own behaviour, this could invariably translate to or lead to a positive ground for intuitive ideas relating to unique business generations.

While many studies have concentrated on various aspects of entrepreneurship as a trending subject, few of them deal with this particular research idea especially as it concerns the variables under study. In as much as literature has indicated that, personality traits, abilities and predispositions attributed to an intuitive decision maker are also mostly consistent with those characteristic of an entrepreneur (Malewska, 2017), then, it can be assumed that people with these features and skills will also be endowed with significant intuitive and entrepreneurial potential. Besides, entrepreneurs are more predisposed to use intuition and take entrepreneurial actions when managing an organization. In the light of the above, the results of these findings will be discussed only in relation to the few literatures directly related to these variables.

The findings of this research find support from similar findings spread across the entrepreneurship literature. For example, Marchisotti, Almeida, and Domingos, (2018) studied decision-making among respondents who are at the first management level with emphasis on the meddling of the organisational culture. Result confirms that managers consider intuitive feeling important in the decision-making process. Among the analyzed factors, organisational culture was confirmed as the weightiest in the ways managers at the first-level of the organisation come to a decision, accounting for $94 \%$ of the variance. Truong, Hallinger, and Sanga (2017) on their own conducted an assiduous, qualitative assessment on how decision-making traditions of Vietnamese school Principals respond to their socio-cultural context. Result revealed that not only the one culture within the organisational affects decision making but, at the same time, the culture of the environment where each individual is raised also has an important role and in most cases actually determines the decision-making process of an individual. In the same vein, Buchtel, and Norenzayan, (2008) examined cultural diversities in the perceived value of analytic versus instinctive way of thinking among people from the Western and Eastern 
cultures. In comparison to Western participants, East Asians judged lateral thinking as more vital and sensible than analytic reasoning.

On the other hand, the result for LOC vis-a-vis El found support in the work of Mehni and Saeidipour, (2016) that investigated the relationships between cognitive styles and entrepreneurship characteristics of undergraduates in Taft Payam Noor University. Results showed that cognitive styles in order of concrete-sequential $45 \%$ (CS), and abstract-sequential 29\% (AS) that are component of intuition exhibited the uppermost significant positive relationship to entrepreneurism features (LOC, need for achievement, creativity, risk taking, tolerance for ambiguity, etc). Likewise, Hozoori et al., (2011) studied the relationship between Gregoric cognitive styles with entrepreneurism attributes of master's students in a University in Vietnam and found significant positive relationships between their cognitive styles and entrepreneurship features with concrete-successive style being of highest correlation among the variables.

The second hypothesis found that there was joint prediction of entrepreneurial cultural support, and locus of control on entrepreneurial intuition among university students. The study finding was in accordance with studies done by (Marchisotti et al., 2018; Truong et al., 2017; Mehni \& Saeidipour, 2016; Hozoori et al., 2011). The rationale behind this finding maybe unconnected to the fact that when the environment is conducive and supportive of entrepreneurship ideas, coupled with the fact that when an individual have the control of his/her behaviour this could invariably translate or generate to better intuitive ideas relating to unique decision generations as all the variables can work together to stimulate positivity.

\section{Conclusion}

This study concludes that ECS and LOC are significant determinant of El among the study sample; as it was confirmed that entrepreneurial intuition increases in the presence of ECS and LOC. Consequentially, it was drawn from the discussion that ECS and LOC had a significant influence on entrepreneurial intuition. Hence, researcher's theoretical predictors of El received a strong support indicating that ECS and LOC should be considered in models of El. Conversely, the use of intuition as a dependent variable has its own weakness because intuition may not distinguish between the "dreamers and the "doers". Although the study has made major findings that are cogent and contributed to knowledge, however, a limitation was observed in the research design which affected the findings of this study. Cross-sectional survey research design made the researcher to be able to gather data at one point in time, hence, downplaying the richness that a longitudinal research would have offered. Again, the fact that little direct research had been done using these variables is another limitation that should be addressed. 


\section{References}

Aboal, D., \& Veneri, F. (2016). Entrepreneurs in Latin America. Small Business Economics, 46(3), 503-525.

Allinson, C.W. \& Hayes, J. (1996) 'The cognitive style index: a measure of intuition-analysis for organizational research', Journal of Management Studies, Vol. 33, No. 1, pp.119-135.

Almahry, F. F., Sarea, A. M., \& Hamdan, A. M. (2018). A Review Paper on Entrepreneurship Education and Entrepreneurs' Skills. Journal of Entrepreneurial Education, 21(Special Issue), 1-7.

Baldacchino, L., Ucbasaran, D., Cabantous, L., \& Lockett, A. (2014). Entrepreneurship Research on Intuition: A Critical Analysis and Research Agenda. International Journal of Management Reviews DOI: 10.1111/ijmr.12056

Bird, B. (1988) 'Implementing Entrepreneurial Ideas: The Case for Intention', Academy of

Management Review, Vol. 13, No. 3, pp.442-453.

Breazeale, N., Fortunato, M.W.-P., Allen IV, J.E., Hustedde, R.J., \& Pushkarskaya, H (2015). Constructing a MultiDimensional Measure of Local Entrepreneurial Culture, Community Development. Journal of Community Development Volume 46, 2015 - Issue 5: Pages 516-540

Castellano, S. Maalaoui, A. Safraou, I \& Reymond, E.(2014). Linking Intuition and Entrepreneurial Intention: A comparative Study Among French and US Student Entrepreneurs. International Journal of Entrepreneurship and Innovation Management, Vol. 18, No. 1, 2014

Cerni, T., Curtis, G., \& Colmar, S. (2014). Cognitive-Experiential. Leadership Model: How Leaders' Information-Processing Systems can Influence Leadership Styles. Journal of Leadership Studies, 8(3), 26-39.

Dane, E. \& Pratt, M. G. (2007). Exploring Intuition And its Role in Managerial Decision Making. Academy of Management Review, 32(1), pp. 33-54.

Entrialgo, M., Fernández, E., \& Vázquez, C. J. (2000). Characteristics of Managers as Determinants of Entrepreneurial Orientation: Some Spanish Evidence, Enterprise and Innovation Management Studies, 1, 2: 187-205.

Epstein, S. (2010) 'Intuition and Decision Making' in Bial Foundation 8th Symposium, Behind and Beyond the Brain. Intuition and Decision-making, 7-10 April, Porto, Portugal.

Epstein, S. (2008) 'Intuition from the Perspective of Cognitive-Experiential Self-theory' in

H. Plessner, C. Betsch and T. Betsch (Eds.): Intuition in Judgment and Decision Making, pp.23-38, Lawrence Erlbaum, Mahwah, NJ.

Epstein, S. (2003). Cognitive-Experiential Self-theory of Personality. In T. Millon \& M. J. Lerner (Eds.), Handbook of Psychology, Personality and Social Psychology (Vol. 5, pp. 159-184). NJ: John Wiley and sons Inc.

Epstein, S., Pacini, S., Heir, H., \& Denes-Raj, V. (1996).Individual Differences in Intuitive-Experiential and Analytical Rational Thinking Styles. Journal of Personality and Social

Psychology, 71(2), 390-405.

Epstein, S. (1991) 'Cognitive-Experiential Self-theory: An Integrative Theory of Personality' in

R. Curtis (Ed.): The Relational Self: Convergences in Psychoanalysis and Social Psychology, pp.111-137, Guilford, New York.

Foss, N.J. \& Lyngsie, J. (2011). The Emerging Strategic Entrepreneurship Field: Origins, Key Tenets, and Research gaps. Strategic Management and Globalization Working Paper, No.7

Harteis, C., Koch, T. \& Morgenthaler, B. (2008) 'How Intuition Contributes to High Performance: An Educational Perspective', US-China Education Review, Vol. 5, No. 1, pp.68-80.

Hodgkinson, G.P., Sadler-Smith, E., Burke, L.A., Claxton, G. \& Sparrow, P. (2009) 'Intuition in Organizations: Some Implications for Strategic Management', Long Range Planning, Vol. 42, No. 3, pp.277-297.

Imafidon, K. (2014). Entrepreneurship Development for Sustaining Economic Growth In Third World Nations. Journal of Emerging Trends in Economics and Management Sciences (JETEMS) 5(7):101-108.

Kickul, J., Gundry, L.K., Barbosa, S.D. \& Whitcanack, L. (2009) 'Intuition Versus Analysis?

Testing Differential Models of Cognitive Style on Entrepreneurial Self-efficacy and Intentionality', Entrepreneurship Theory and Practice, Vol. 33, No. 2, pp.439-453.

Lank, A.G., \& Lank, E.A. (1995). Legitimizing the Gut Feel: The Role of Intuition in Business, Journal of Managerial Psychology, 1995, 10(5), pp. 18-23.

Laszczak, M. (2010) Intuicja w podejmowaniu decyzji strategicznych, Wydawnictwo ATH, Bielsko-Biała 2010.

Malewska, K. (2018). Intuition and Entrepreneurship in Business Practice. Proceedings of the $6^{\text {th }}$ International Conference on Management, Leadership and Governance ICMLG 2018, Bangkok University. Academic Conferences and Publishing International Ltd, s. 167-172.

Mazzarol, T., Volery, T., Doss, N., \& Thein, V. 1999 Factors Influencing Small Business Start-ups, International Journal of Entrepreneurial Behaviour and Research, 5, 2: 48-63. 
McMullen, J. S., \& Shepherd, D. A. (2006). Entrepreneurial Action And The Role of Uncertainty in the Theory of the Entrepreneur. Academy of Management Review, 31(1), 132-152.

Müller, S.L. \& Thomas, A.S. (2001). Culture and entrepreneurial potential: A nine-country study of locus of control and innovativeness. Journal of Business Venturing 16 (1): 51-75.

Mitchell, J. R., Friga, P. N., \& Mitchell, R. K. (2005). Untangling the Intuition mess: Intuition as a Construct in Entrepreneurship Research. Entrepreneurship Theory and Practice, 29(6) 653-679.

Millet, P. (2005) Locus of Control and its Relation to Working Life: Studies from the Fields of Vocational Rehabilitation and Small firms in Sweden. Department of Human Work Science, Luleå University of Technology Sweden.

Miller, D. (1983). The Correlates of Entrepreneurship in Three Types of Firms. Management Science, 29, 770-791.

Mills K. (2012) Invisible Genius; The Intuition Secrets of the World's Greatest Leaders and How to Profit from Them. Imaginicity publishers.

Nhuta, S., \& Kapofu, W. (2015). Evaluation of Strategic Entrepreneurship Approaches for Sustainable Growth in the Commercial Banking Sector in Zimbabwe. International Journal of Contemporary Applied Sciences, 2 (2): 57-83.

Oyeleke J, T., Ojewumi, K. A., Adedayo, O., .... \& Oguntayo, R., (2018). Perceived Entrepreneurial Behaviour as Predictor of Entrepreneurial Intention Among University of Ibadan Undergraduate Students. Ife Journal of Behavioural Research

Pheysey, D.C (1993). Organizational Cultures. Types and Transformations. Routledge, London and New York, 1993.

Plecher, H. (2020). Youth Unemployment Rate in Nigeria in 2020. Access on the $14^{\text {th }}$ April, $2020 @$ https://www.statista.com/aboutus/our-research-commitment

Rotter, J.B. (1996). "Generalized Expectancies For Internal Versus External Control of Reinforcement," Psychological Monographs: General and Applied 80 (1966): 1-21.

Rotter, J. B. (1992). "Cognates of Personal Control: Locus of control, Self-Efficacy, and Explanatory style": Comment. Applied and preventive Psychology Spring Volume 1 Issue 2 pp. 127-129.

Rowan, R., 1986. The intuitive manager, Boston, Toronto: Little Brown and Company.

Sadler-Smith, E. \& Shefy, E. (2004) 'The intuitive Executive: Understanding And Applying 'Gut Feeling' in Decision-Making', Academy of Management Executive, Vol. 18, No. 4, pp.76-91.

Schein, E. H. (2010). Organizational Culture and Leadership, Wiley Imprint, 4th Ed, 2010.

Simon, H.A., (1987). Making Management Decisions: The Role of Intuition And Emotion. Academy of Management Executive 1, 57-64.

Shoemaker, P.J., \& Vos, T.P (2009). Media Gatekeeping, In: Stacks, D.W., Salwen, M.B. (Ed.): An Integrated Approach to Communication Theory and Research, New York. 2009, pp.75-89.

Steinbauer, R., Rhew, N.D., Kinnamon, E., \& Fabian, F (2014). The Conflicting Drivers of Entrepreneurial Ethics. Journal of Ethics \& Entrepreneurship, Vol. 4, No. pp. 57-72

Umukoro, S., \& Okurame, D. (2017). Exogenous Determinants of Entrepreneurial Intuition and the Mediatory Role of Psychological Capital Among Potential Youth Entrepreneurs. Journal of Global Entrepreneurship Research volume 7, Article number: 19

Vodă, I. A., \& Nelu, F. (2019). Impact of Personality Traits and Entrepreneurship Education on Entrepreneurial Intentions of Business and Engineering Students. Sustainability, 11(1192), 1-19 https://doi.org/10.3390/su11041192. 